\title{
Multilayer Corrosion of Aluminum Activated by Lead
}

\author{
Anawati, ${ }^{\mathrm{a}, *}$ Brit Graver, ${ }^{\mathrm{a}}$ Heidi Nordmark, ${ }^{\mathrm{c}}$ Zhijun Zhao, ${ }^{\mathrm{d}}$ G. S. Frankel, ${ }^{\mathrm{d}, * *}$ \\ John Charles Walmsley, ${ }^{\text {b,c }}$ and Kemal Nisancioglu ${ }^{a, * * *, z}$ \\ ${ }^{a}$ Department of Materials Science and Engineering, and ${ }^{b}$ Department of Physics, Norwegian University of \\ Science and Technology, N-7491 Trondheim, Norway \\ ${ }^{c}$ SINTEF Materials and Chemistry, N7465 Trondheim, Norway \\ ${ }^{d}$ Fontana Corrosion Center, Ohio State University, Columbus, Ohio 43210, USA
}

\begin{abstract}
Segregation of $\mathrm{Pb}$ as a nanofilm between the thermal oxide and the metal substrate as a result of high temperature heat-treatment is known to activate aluminum alloys anodically in chloride solution. The relationship between the oxidation peaks in the polarization curve and corrosion morphology was investigated by the use of a video technique during electrochemical polarization. A model binary $\mathrm{Al}-\mathrm{Pb}$ alloy containing $20 \mathrm{ppm} \mathrm{Pb}$, which was annealed at $600^{\circ} \mathrm{C}$, showed two oxidation peaks at -0.95 and $-0.88 \mathrm{~V}_{\mathrm{SCE}}$. The video measurements revealed superficial etching of the surface by selective oxidation of the aluminum metal twice, followed each time by repassivation, as the two oxidation peaks were resolved during anodic potentiodynamic sweep. Ex situ scanning and transmission electron microscopy of the corroded specimens indicated that the first layer of etching followed the $\mathrm{Pb}$ film and undermined the thermal oxide, which remained attached to the metal surface at discrete locations, thereby forming a crevice. The second layer of attack was caused by crevice corrosion of the aluminum substrate in the crevice formed by the preceding oxidation process, which resulted in the removal of the attached thermal oxide film. The exposed aluminum substrate started to pit as the pitting potential was finally exceeded.
\end{abstract}

(C) 2010 The Electrochemical Society. [DOI: 10.1149/1.3478663] All rights reserved.

Manuscript submitted April 9, 2010; revised manuscript received July 20, 2010. Published August 17, 2010.

Lead, which is present as a trace element in almost all aluminum alloys at the ppm level, has recently received significant attention because of its role in anodically activating aluminum alloys in chloride media. ${ }^{1-6}$ Activation was attributed to $\mathrm{Pb}$ segregating in the form of a nanosized metallic film, as well as particles, at the oxidemetal interface as a result of annealing at $600^{\circ} \mathrm{C}$, and thereby destabilizing the oxide in chloride solution. ${ }^{4-7}$ The lead particles were not as efficient activators as the film due to their poor wetting of the surface. The $\mathrm{Pb}$ film was formed by the entrapment of the $\mathrm{Pb}$ segregating during heat-treatment between the thermally formed $\gamma-\mathrm{Al}_{2} \mathrm{O}_{3}$ crystals and the aluminum substrate.

Activation is characterized by a significant decrease in the corrosion potential of the $\mathrm{Pb}$-containing alloy relative to pure aluminum and high anodic output at potentials below the pitting potential, where aluminum is expected to be passive, as shown in Fig. 1. For lead concentration from 5 to $50 \mathrm{ppm}$, the anodic polarization curve of activated aluminum is similar to the curve shown for $20 \mathrm{ppm} \mathrm{Pb}$ in Fig. 1. ${ }^{4}$ The anodic polarization curve furthermore contains two apparent oxidation peaks, the nature of which is not yet understood. ${ }^{5}$ The purpose of the present work is to provide new electron-optical imaging and in situ video measurements for the development of corrosion morphology during potentiodynamic polarization of a model $\mathrm{Al}-\mathrm{Pb}$ alloy in chloride solution to explain the cause of oxidation peaks and obtain a better understanding of the underlying corrosion mechanism.

\section{Experimental}

The material used was a binary $\mathrm{Al}-\mathrm{Pb}$ model alloy prepared from pure components. Aluminum containing $20 \mathrm{ppm}$ lead was cast into $2.3 \mathrm{~cm}$ thick slabs and cold-rolled down to a thickness of $2.2 \mathrm{~mm}$. The samples were metallographically polished through $1 \mu \mathrm{m}$ diamond paste. The polished samples were then annealed in an air circulation furnace for $1 \mathrm{~h}$ at $600^{\circ} \mathrm{C}$ and then quenched in distilled water as in earlier work. ${ }^{5}$

The specimens were mounted in screw-cap holders and were then potentiodynamically polarized in $5 \mathrm{wt} \% \mathrm{NaCl}$ solution at $25 \pm 1{ }^{\circ} \mathrm{C}$. The cell geometry, including the positioning of the electrodes and the solution volume, were identical in all the runs, except where the corrosion on the surface was video-filmed in situ. The

\footnotetext{
* Electrochemical Society Student Member.

** Electrochemical Society Fellow.

*** Electrochemical Society Active Member

z E-mail: kemaln@material.ntnu.no
}

potentiodynamic sweep rate was varied in the range from 0.03 to 0.1 $\mathrm{mV} / \mathrm{s}$. The potential was swept in the positive potential direction starting from $-50 \mathrm{mV}$ below the open-circuit potential. In certain runs, the sweep was interrupted at predetermined potentials and the sample was removed from the cell, washed, and dried for subsequent scanning electron microscopy (SEM) and transmission electron microscopy (TEM) characterizations of the corrosion morphology obtained. The electrochemical apparatus and procedure used in these conventional electrochemical polarization tests (without in situ video filming) have been discussed in detail in earlier work. ${ }^{1-7}$

Some of the samples were masked by acetone-based stop-off lacquer Miccrostop to expose areas of $\sim 0.03$ to $0.04 \mathrm{~cm}^{2}$ for in situ observation under an optical microscope during the electrochemical polarization tests. The electrochemical cell used for these measurements was designed to expose the samples horizontally, with the test section facing upwards, for easy observation of the corroding surface by the optical microscope. Mechanical stirring was not used, and the tests were run in ambient laboratory conditions without temperature control. The details about this technique, including the synchronization of the video and the polarization curve, have been reported. ${ }^{8}$

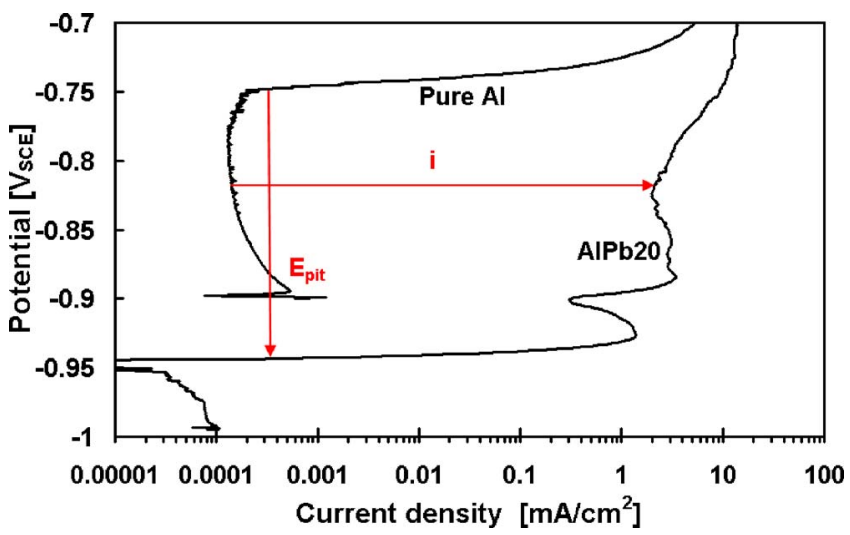

Figure 1. (Color online) Polarization curves for pure aluminum and an $\mathrm{Al}-\mathrm{Pb}$ model alloy containing $20 \mathrm{ppm} \mathrm{Pb}$ at a potential sweep rate of 0.1 $\mathrm{mV} / \mathrm{s}$ in $5 \mathrm{wt} \% \mathrm{NaCl}$ solution. ${ }^{4}$ The samples were annealed for $1 \mathrm{~h}$ at $600{ }^{\circ} \mathrm{C}$ and quenched in water. The red arrows indicate the reduction of the pitting potential and increased anodic current density of $\mathrm{Al}-\mathrm{Pb}$ alloy compared to pure aluminum as a result of activation by alloyed $\mathrm{Pb}$. 

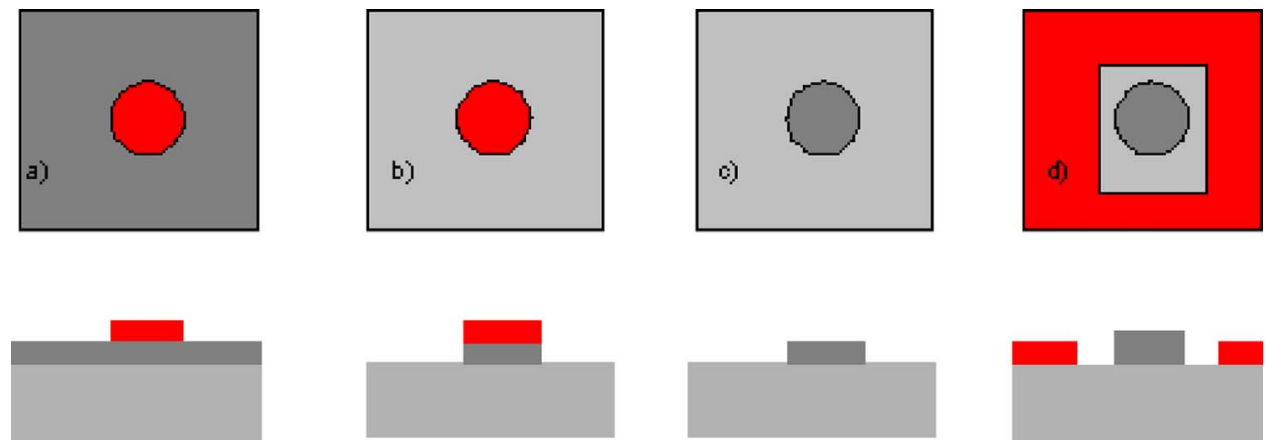

Figure 2. (Color online) Sketch of the procedure used for preparation of crevice-free samples according to the method described in Ref. 8. The first row shows the top-view, and the second row shows the cross section of the sample. (a) A nearly circular area of size $0.25 \mathrm{~cm}^{2}$ (red) in the middle of a rectangular specimen was coated with the masking lacquer. (b) The remaining area (gray) was etched by potentiostatic polarization at $-0.8 \mathrm{~V}_{\mathrm{SCE}}$, removing the active layer. (c) The lacquer was removed with acetone, revealing the active layer remaining underneath (dark gray). (d) The sample was masked again, exposing the active layer and part of the etched surface.

Because of crevice corrosion of the susceptible surface layer under the screw-cap holder and masking lacquer in the two types of experiments, which affected the polarization curve, attempts were made to prepare "crevice-free" samples. One procedure ${ }^{8}$ involved the application of masking lacquer over a small area of the sample surface, as shown in Fig. 2a. The bare surface around the masked area was etched by potentiostatic polarization at $-0.8 \mathrm{~V}_{\mathrm{SCE}}$ to remove the active layer there, as shown in Fig. 2b. The lacquer was next removed with acetone, exposing the active layer underneath (Fig. 2c). The sample was masked again, as shown in Fig. 2d, leaving the active layer and part of the etched surface exposed.

In the other method, a Teflon ring with a sharp edge was physically pressed on the sample to inscribe a circular notch of $\sim 500 \mu \mathrm{m}$ depth, which exposed a relatively $\mathrm{Pb}$-free passive bulk metal in the notch. A screw-cap specimen holder was used to apply an even force, giving a uniformly deep inscription. The area outside the circular notch was masked with lacquer. The area inside was the test area exposed to the solution. The notch functioned as a physical barrier against initiation and propagation of crevice corrosion under the lacquer mask.

Field-emission gun (FEG)-SEM and FEG-TEM were used for the post mortem investigation of the corroded samples, which were potentiodynamically polarized to preselected potentials along the polarization curve. The FEG-SEM examination was performed in plan view, and FEG-TEM characterization was on cross-sectional foils of the corroded surface.

TEM cross-sectional foils were prepared using procedures discussed in detail in earlier work. ${ }^{4-7}$ Two replicate corroded surfaces were first glued together with epoxy. The glued sample was then cut into $1 \mathrm{~mm}$ thick slices perpendicular to the corroded surfaces by using a rotating diamond blade metallographic cutter. These were mechanically ground to $\sim 100 \mu \mathrm{m}$ thickness and then thinned further using a dimple grinder, yielding a sample thickness of $\sim 30 \mu \mathrm{m}$ at the corroded surface region. Finally, electron transparency was achieved by using a Gatan Precision Ion Polishing System at an ion-milling angle of $4^{\circ}$ with $4 \mathrm{kV}$ beam energy. TEM observation was performed by using JEOL 2010F FEG-TEM at $200 \mathrm{kV}$ electron accelerating voltage. The microscope was equipped with an INCA energy-dispersive X-ray spectrometer (EDS).

\section{Results}

In situ observation of corrosion morphology.- Figure 3 shows polarization data for the as-polished and annealed $\mathrm{Al}-\mathrm{Pb}$ samples obtained at a sweep rate of $0.1 \mathrm{mV} / \mathrm{s}$. The images of the corroded surface at points A-F in Fig. 3, which were selected from the video film obtained during the potentiodynamic polarization experiment, are shown in Fig. 4. The surface was passive at the start potential of $-1.0 \mathrm{~V}_{\mathrm{SCE}}$, as shown in Fig. 4a. Corrosion initiated in the grain bodies close to the grain boundaries at $-0.95 \mathrm{~V}_{\mathrm{SCE}}$ and propagated two dimensionally, as shown in Fig. 4b and c, respectively. Corrosion occurred along the interface between the thermally formed oxide and metal, as will further be documented below, with the oxide still remaining on the surface. Corrosion propagation under the film could be imaged optically through the transparent oxide film. The small, circular black spots on the corroding surface were hydrogen gas bubbles attached to the surface. The gas formed on the corroding surface and escaped through cracks on the undermined oxide. In contrast to the earlier ex situ observations, ${ }^{4}$ there was no obvious corrosion initiation at the grain boundaries. The grain boundaries in fact functioned as physical barriers against the spreading of the twodimensional attack from one grain to the next, as can be observed in Fig. 4c.

The first maximum in the polarization curve (point C) occurred as corrosion spread laterally over the exposed surface. The entire exposed sample surface was superficially etched under the oxide except for a few uncorroded spots, as shown in Fig. 4d, corresponding to the first minimum in the polarization curve (point D in Fig. 3). The minimum in the curve was at about $-0.9 \mathrm{~V}_{\mathrm{SCE}}$, and diminishing visible corrosion activity indicated that the surface repassivated as the first layer of surface metal was corroded away from the surface, with the exception of the spots that remained passive.

Corrosion initiated again as the potential was further increased in the noble direction, and an apparently new layer started corroding with a simultaneous increase in the anodic current density, as shown at point $\mathrm{E}$ in Fig. 3 and the corresponding image in Fig. 4e. Corro-

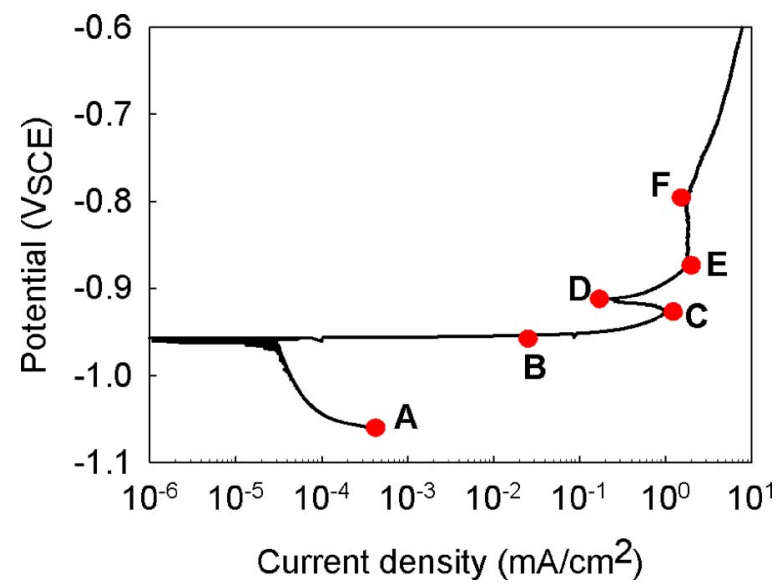

Figure 3. (Color online) Polarization curve of an Al-Pb sample obtained at a sweep rate of $0.1 \mathrm{mV} / \mathrm{s}$. A-F are the points on the polarization curve at which the corresponding images of the corroded surface, shown in Fig. 4, were taken. 

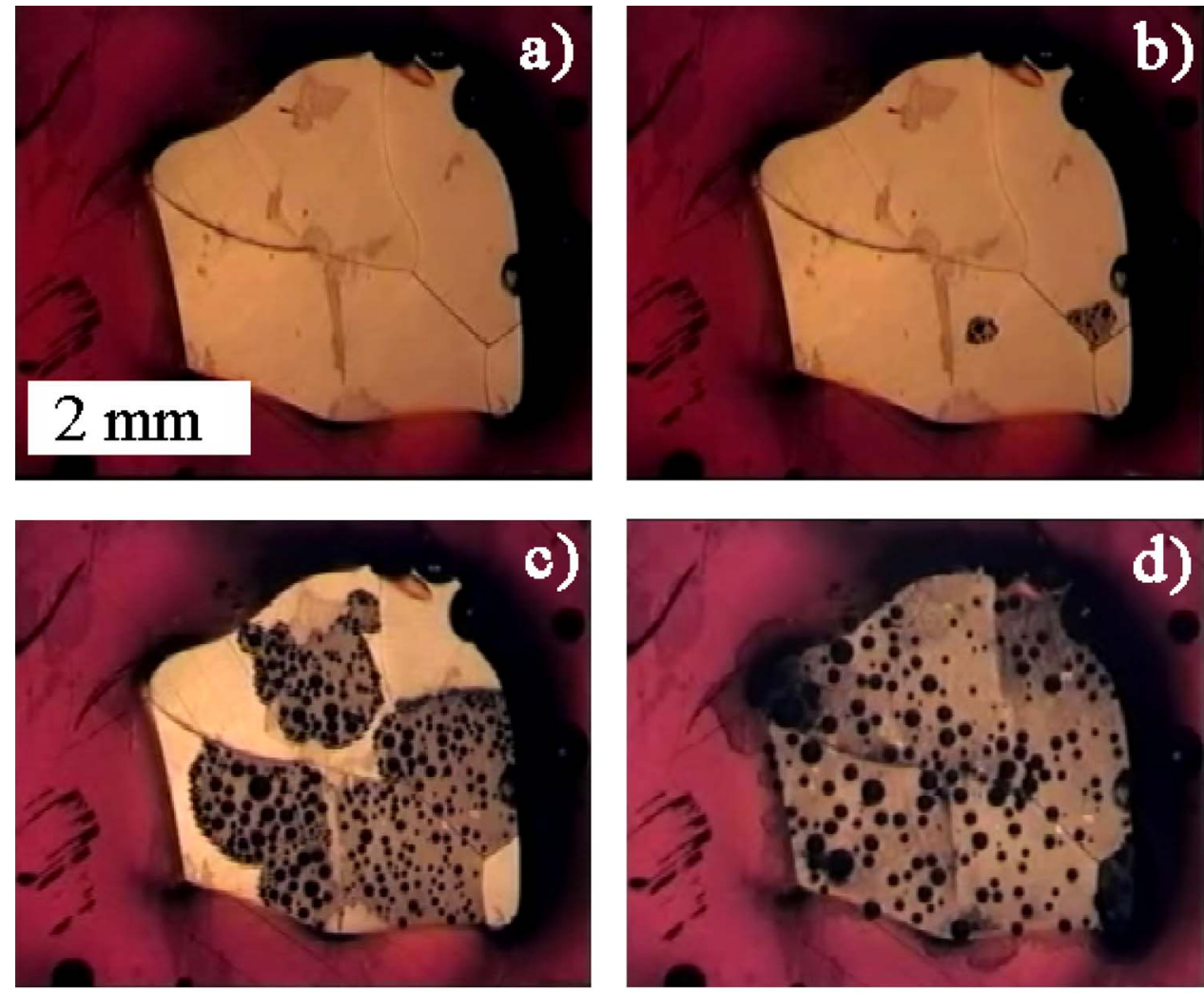

Figure 4. (Color online) Development of corrosion morphology on the $\mathrm{Al}-\mathrm{Pb}$ sample during potentiodynamic polarization. The morphologies a-f correspond to the points A-F, respectively, on the polarization curve in Fig. 3.
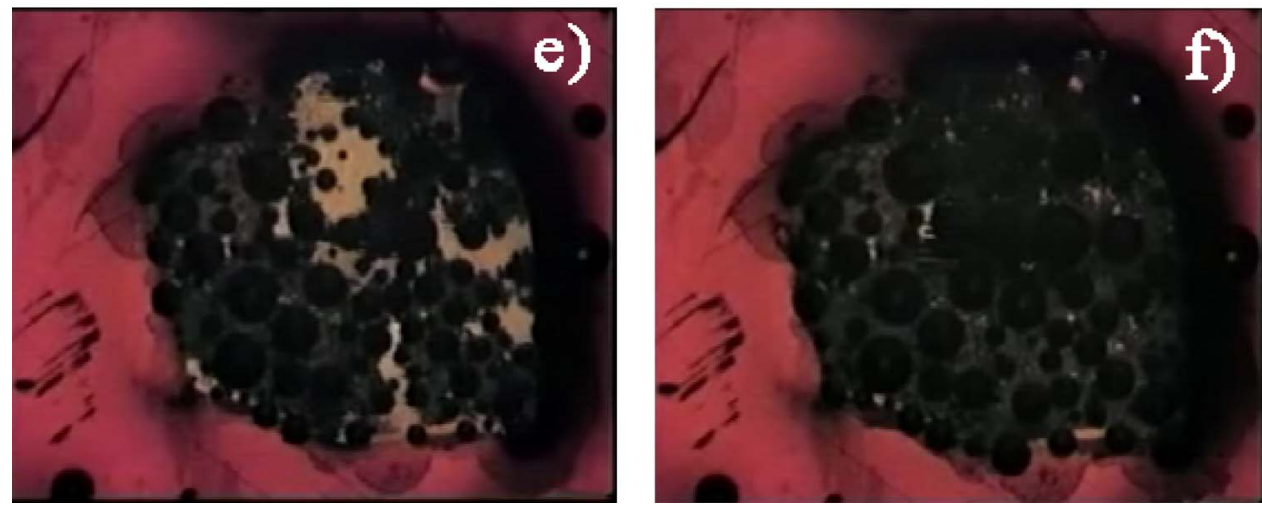

sion was easily observed due to the formation and growth of a perimeter of darker areas on the corroding surface, indicating a coarser corrosion morphology in relation to the first activation peak, although the attack was still superficial. A second anodic peak was observed at $-0.88 \mathrm{~V}_{\mathrm{SCE}}$ as the second layer of corrosion spread over the surface, and a new state of passivity appeared to develop as the current density started to decrease again to a second minimum. At this point, labeled $\mathrm{F}$ in Fig. 3, most of the second layer, with the exception of a few spots still remaining passive from the first minimum, was removed (Fig. 4f).

Most of the undermined oxide film remained on the surface up to point $\mathrm{F}$ on the polarization curve, probably loosely attached to the metal at discrete points. The film was finally torn off the surface between points $\mathrm{E}$ and $\mathrm{F}$ on the curve by vigorous gas evolution on the corroding areas. Above $-0.78 \mathrm{~V}_{\mathrm{SCE}}$, which corresponds to the critical pitting potential of pure aluminum in $5 \% \mathrm{NaCl}$ solution, ${ }^{9}$ extensive hydrogen evolution resulting from pitting corrosion of the newly exposed surface started obscuring the image of the corroding surface.

The second peak in Fig. 3 was not clearly resolved at the potential sweep rate of $0.1 \mathrm{mV} / \mathrm{s}$. By reducing the sweep rate, a clearer resolution of the peaks was obtained on the polarization curve, as shown in Fig. 5. In these runs, video imaging of the corrosion morphology showed more clearly that the layers of lateral attack corresponding to successive active peaks were complete, i.e., no uncorroded grains remained after the resolution of each peak. The current minima following the two activation peaks corresponded with a temporary passivation of the surface.

The thickness of aluminum layers oxidized during the first two stages of corrosion was estimated by integrating the area under the peaks of curve b in Fig. 5 with respect to a baseline as sketched in the figure. The result obtained was $\sim 50$ and $200 \mathrm{~nm}$ for the first and second stages of corrosion, respectively. Possible expansion of the crevice by formation of solid corrosion products was not taken into account in the calculation.

Post mortem SEM investigation.- The surface morphology resulting from the different stages of corrosion was investigated in more detail by the ex situ SEM observation. The samples were prepared by potentiodynamic polarization up to selected potentials at 


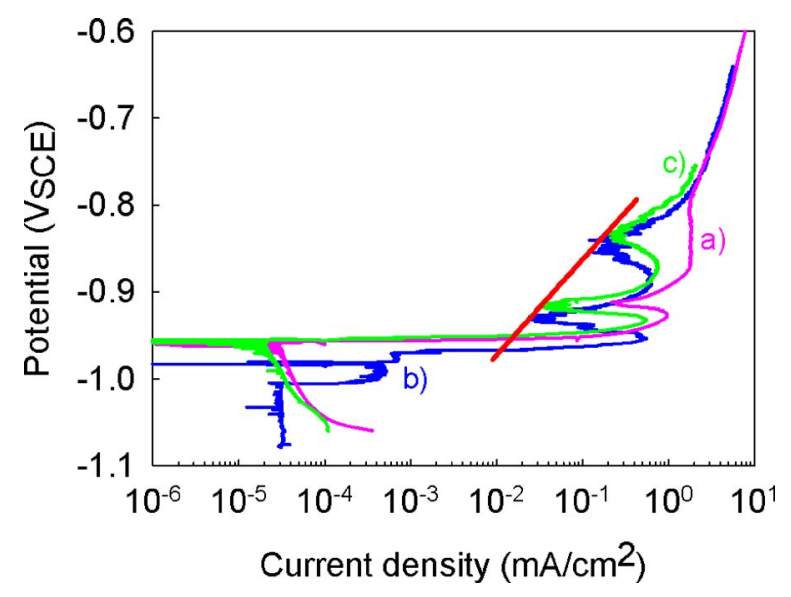

Figure 5. (Color online) Potentiodynamic polarization curves for the crevice-free $\mathrm{Al}-\mathrm{Pb}$ samples obtained at the sweep rates of (a) 0.1 , (b) 0.05 , and (c) $0.03 \mathrm{mV} / \mathrm{s}$ in $5 \mathrm{wt} \% \mathrm{NaCl}$ solution at $25^{\circ} \mathrm{C}$. The red straight line is the baseline for obtaining the area under the peaks of curve $b$, as discussed in the text.

which the potential sweep was terminated. The sample was immediately removed from the cell, rinsed in distilled water, and dried before SEM investigation.

Figure 6a shows the SEM image of a sample polarized to -0.95
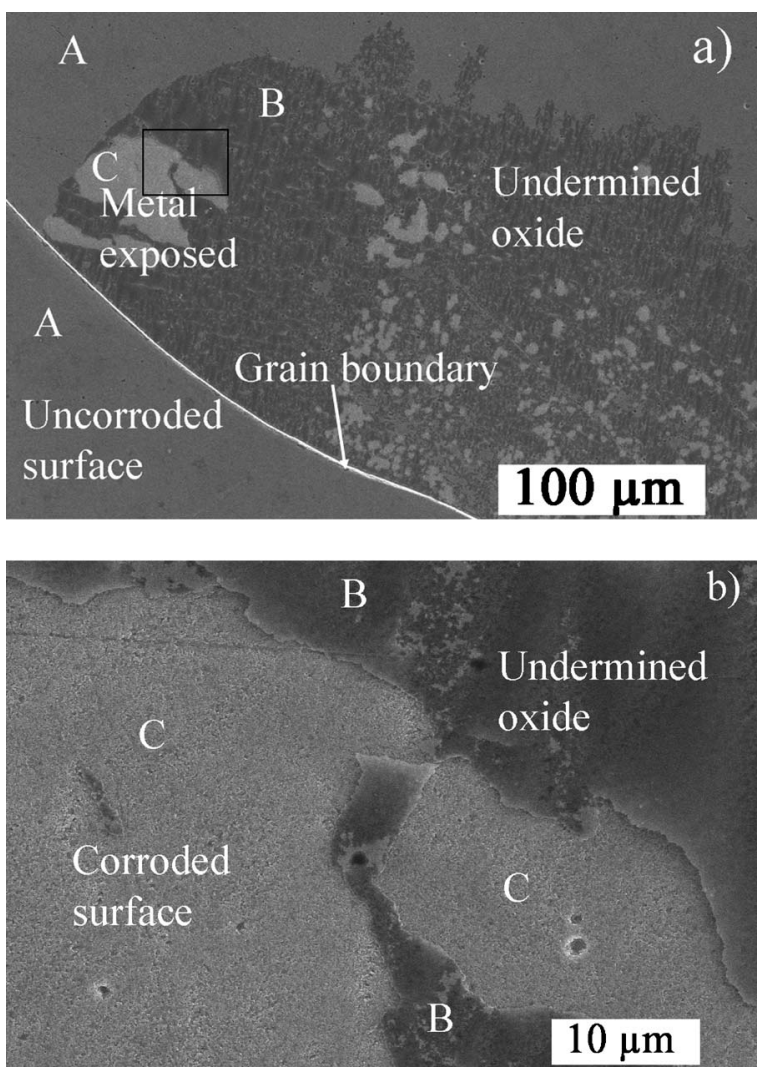

Figure 6. Secondary electron image of typical corrosion morphology resulting from potentiodynamic polarization of a sample up to $-0.95 \mathrm{~V}_{\mathrm{SCE}}$, corresponding to the first layer of corrosion. (a) The (B) dark gray and (C) light gray areas are corroded in the figure. The dark gray area B is the undermined thermally formed oxide film. The etched metal surface is exposed at the light gray area around point $C$ by removal of the undermined film. The medium gray areas A are not corroded. (b) Higher magnification micrograph of area around point $\mathrm{C}$ in (a), marked by a white square.
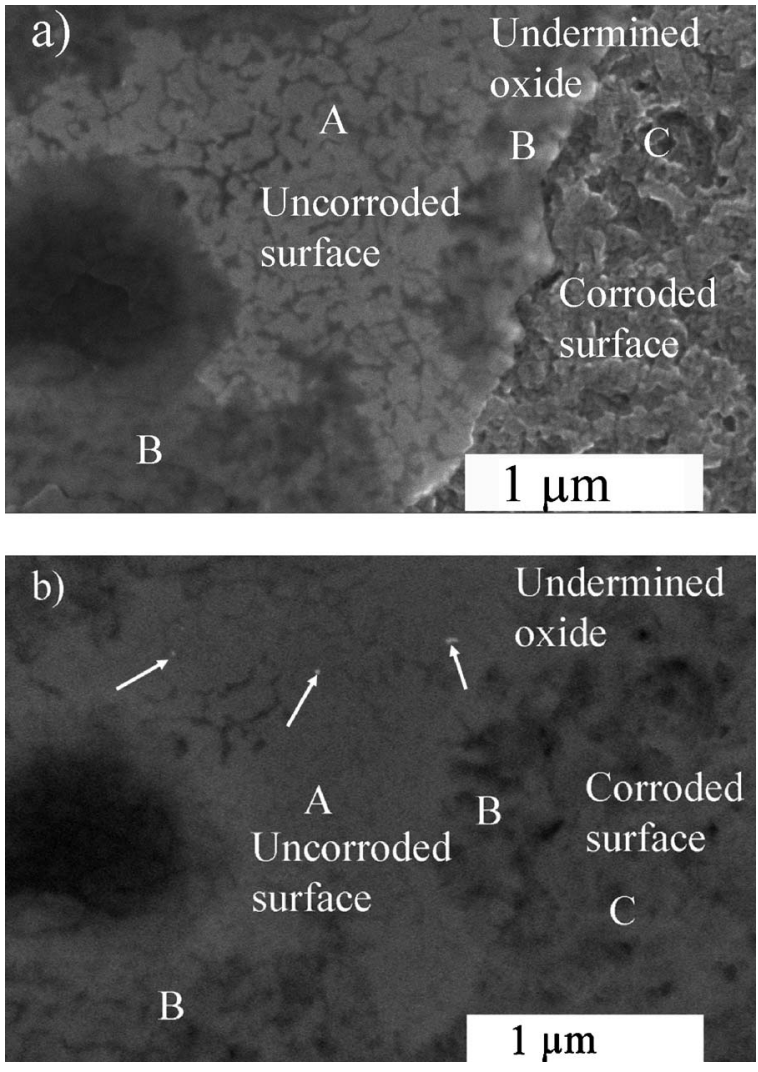

Figure 7. (a) Secondary and (b) backscattered electron image of partly corroded area obtained by potentiodynamic polarization up to $-0.95 \mathrm{~V}_{\mathrm{SCE}}$. Most of the undermined oxide was removed from the corroded area $(\mathrm{C})$. A small area of undermined oxide (B) can be observed close to the boundary between the apparently uncorroded (A) (thermally formed oxide still intact) and the corroded area. Arrows show $\mathrm{Pb}$ particles segregated under the oxide.

$\mathrm{V}_{\mathrm{SCE}}$. The medium gray areas (marked A) were not yet corroded at that potential level, as indicated by the in situ video observation. The dark gray area with apparent roughness (marked B) containing the light gray patches (marked C) was the area affected by the corrosion corresponding to the first anodic peak. The higher magnification micrograph (Fig. 6b) of the area shown in Fig. 6a by a black rectangular frame indicated that the dark areas $\mathrm{B}$ were formed by the undermining of the thermally formed $\gamma-\mathrm{Al}_{2} \mathrm{O}_{3}$ layer, parts of which were removed, probably mechanically during rinsing, giving rise to the light gray areas $\mathrm{C}$ of underlying metal exposed. The undermined oxide was still attached to the surface, probably at discrete points, indicating that the undermining was not entirely uniform, following active areas at the metal-oxide interface. The corrosion morphology of the exposed metal had the appearance of light acid etching. Further evidence about the undermined oxide morphology is given in the next section by the use of cross-sectional TEM images of the corroded surface.

The corrosion front between the corroded zone B and unaffected zone A was further investigated in Fig. 7. Figure 7a shows the secondary electron image of a boundary between the partially undermined oxide and the adjacent corroded area, where the undermined thermal oxide was removed, such that the first layer corrosion morphology can be observed. The oxide-covered area includes both the undermined and uncorroded regions. Submicrometer size pits were observed in the oxide-free area, which were possibly acid etch tunnels formed during the first stage of etching. The uncorroded thermal oxide exhibited the typical morphology of $\gamma-\mathrm{Al}_{2} \mathrm{O}_{3}$ crystals (gray) with pores between the crystals (elongated dark gray regions), which are known to be filled with amorphous oxide. ${ }^{5,10}$ This porous morphology is typical for the uncorroded surface in general, i.e., 

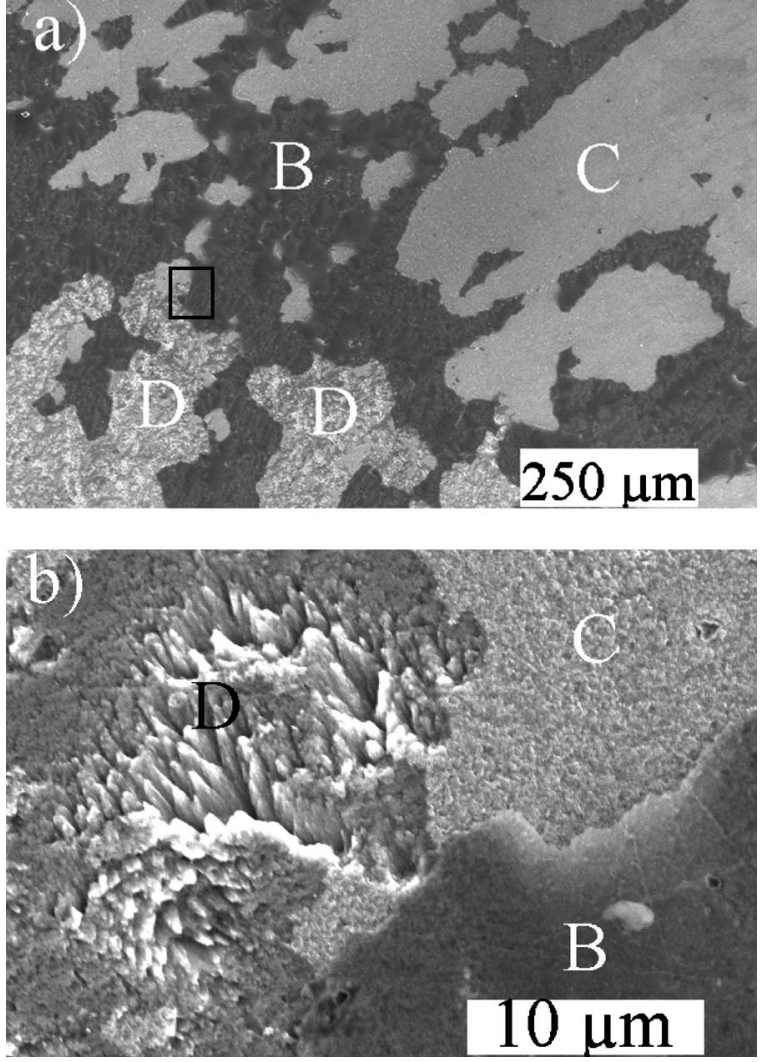

Figure 8. Secondary electron images of the corrosion morphology obtained by potentiodynamically polarizing a sample up to $-0.88 \mathrm{~V}_{\mathrm{SCE}}$ at two different magnifications. (b) is the magnified area shown by a black square in (a). Areas B show undermined oxide by first stage of etching, areas $\mathrm{C}$ are first stage etched areas with the oxide removed, and areas D are second stage etched areas with the oxide removed.

areas marked A in Fig. 6 and 7, some of which are far from any corrosion front. The backscattered electron image of the same area, shown in Fig. 7b, shows segregated nanosize $\mathrm{Pb}$ particles, shown by arrows, as confirmed by the EDS analysis. These particles were still covered by the oxide. This area was also affected by underfilm etching, although this was invisible from the SEM micrographs. Otherwise, it is impossible to explain why the $\mathrm{Pb}$ particles were not visible under the oxide on uncorroded areas which were more than a few micrometers away from the corrosion front. The nanosized $\mathrm{Pb}$ particles at the corrosion front were also observed earlier on similarly corroded specimens. ${ }^{5}$ As in the earlier work, $\mathrm{Pb}$ could not be detected on the corroded surface where the oxide was detached. The $\mathrm{Pb}$ particles were removed with the oxide when it was detached from the surface.

Figure 8 shows the corrosion morphology obtained by potentiodynamically polarizing a sample to a more noble potential of -0.88 $\mathrm{V}_{\mathrm{SCE}}$, at which point the onset of the second layer of corrosion occurred. In Fig. 8a, some of the features described in Fig. 6, viz., dark gray areas exhibiting the first stage of corrosion with remnants of undermined oxide still attached to the surface (area B), and light gray regions where the undermined oxide was removed, revealing the superficially etched metal underneath (area C), are still visible. In the area close to the left bottom margin of the figure, smaller light gray patches with a rougher etch morphology can be observed (area D). These correspond to the second stage of corrosion (second activation peak), which was observed from the video film to occur in the crevice formed between the metal and the undermined film.

The surface with rougher etch morphology resulting from the second stage of corrosion is shown in Fig. 8b at a higher magnification (area D). Areas B and C in Fig. 8b represent the morphology of the first layer of corrosion, respectively, with the oxide still attached to the surface and the oxide removed. The second layer attack was deeper than the first layer, resulting in a rougher morphology. No lead was observed at such areas by SEM.

The areas free from the thermally grown oxide in Fig. 6-8 were probably obtained when the samples were rinsed after the polarization experiment, i.e., these areas were not bared naturally during the polarization experiment. From the videos, the oxide was observed to be detached from the surface as a result of the increasing rate of hydrogen evolution as the potential significantly exceeded the potential of the second peak (point F in Fig. 3).

Post mortem TEM investigation.-Figure 9a shows a brightfield TEM image of the near surface cross section of a sample that was polarized potentiodynamically up to $-0.95 \mathrm{~V}_{\mathrm{SCE}}$, which is in the range of the first phase of attack. The image includes both the uncorroded and corroded regions, covered by a continuous thermally formed oxide $\sim 50 \mathrm{~nm}$ thick. The crystalline features of the oxide, visible in the figure, were confirmed to be $\gamma-\mathrm{Al}_{2} \mathrm{O}_{3}$ by measuring lattice parameters from high resolution transmission electron microscopy (HRTEM) image, as shown in the inserted image. The method was discussed in detail in earlier work. ${ }^{4,5}$ The thickness of the corroded area was in the range 45-60 nm, which agrees well with the result obtained for the first layer of corrosion from the electrochemical data, as reported above.

Figure 9b shows a dark-field scanning transmission electron microscopy (STEM) image of the corroded area, where the nanosized $\mathrm{Pb}$ particles and remnants of the $\mathrm{Pb}$ film are observable, as indicated by the red and white arrows, respectively. Dark-field STEM contrast has been used previously to show the presence of the segregated elements, ${ }^{7}$ making use of the relatively strong scattering for heavier elements. The EDS analysis of one of the particles shown by the red arrow on the right in Fig. 9b is in Fig. 9c. The $\mathrm{Cu}$ peak in the spectrum originated from the copper specimen holder. The particles are attached to the $\gamma-\mathrm{Al}_{2} \mathrm{O}_{3}$ crystals, which were detached from the aluminum metal during the first stage of corrosion. The EDS analysis indicated the presence of remnant $\mathrm{Pb}$ film, shown by white arrows in Fig. 9b, as well as particles on the aluminum metal surface. In the crevice formed between the metal and oxide by corrosion, $\mathrm{Al}$, $\mathrm{O}$, and $\mathrm{Cl}$ were detected by EDS. No crystalline features were detected in the HRTEM diffraction analysis of the products, indicating the presence of amorphous corrosion products in the crevice. These products were probably aluminum chloro-oxides, which are expected to form as a result of localized corrosion of aluminum in chloride media. Figure 9d shows a dark-field image of the crevice tip in Fig. 9a at a higher magnification. The morphology of the corrosion front undermining the oxide and the uncorroded area, where adhesion of the oxide to the metal surface is not affected, can be clearly observed in this figure. The oxide-metal interface of the uncorroded area on the left side of the image shows a nanosized film in bright contrast marked by white arrows, which was characterized by EDS as a Pb-rich film.

Figure 10a shows the cross-sectional TEM images of a typical corroded section of a sample surface polarized up to $-0.88 \mathrm{~V}_{\mathrm{SCE}}$, corresponding to the second stage of attack. The remnants of the thermally formed oxide in the form of individual $\gamma-\mathrm{Al}_{2} \mathrm{O}_{3}$ crystals embedded in the dark gray corrosion product can be seen in the crevice indicated by black arrows. The amorphous corrosion product filled the crevice gap. Loosely adhering oxide was lost during specimen preparation together with the epoxy resin from the top surface of the corrosion product. The depth of attack was not uniform because of the rougher corrosion morphology resulting from the second stage of corrosion in relation to the first stage, as documented by the SEM results above, in particular, area D in Fig. 8a. The thickness of the corroded area was in the range of 60-200 nm, which is on the average larger than the first attack but somewhat smaller than the calculated result based on the integration of the area under the oxidation peaks in the polarization curve. Figure 10b shows a dark-field STEM image of the same sample, but at a differ- 

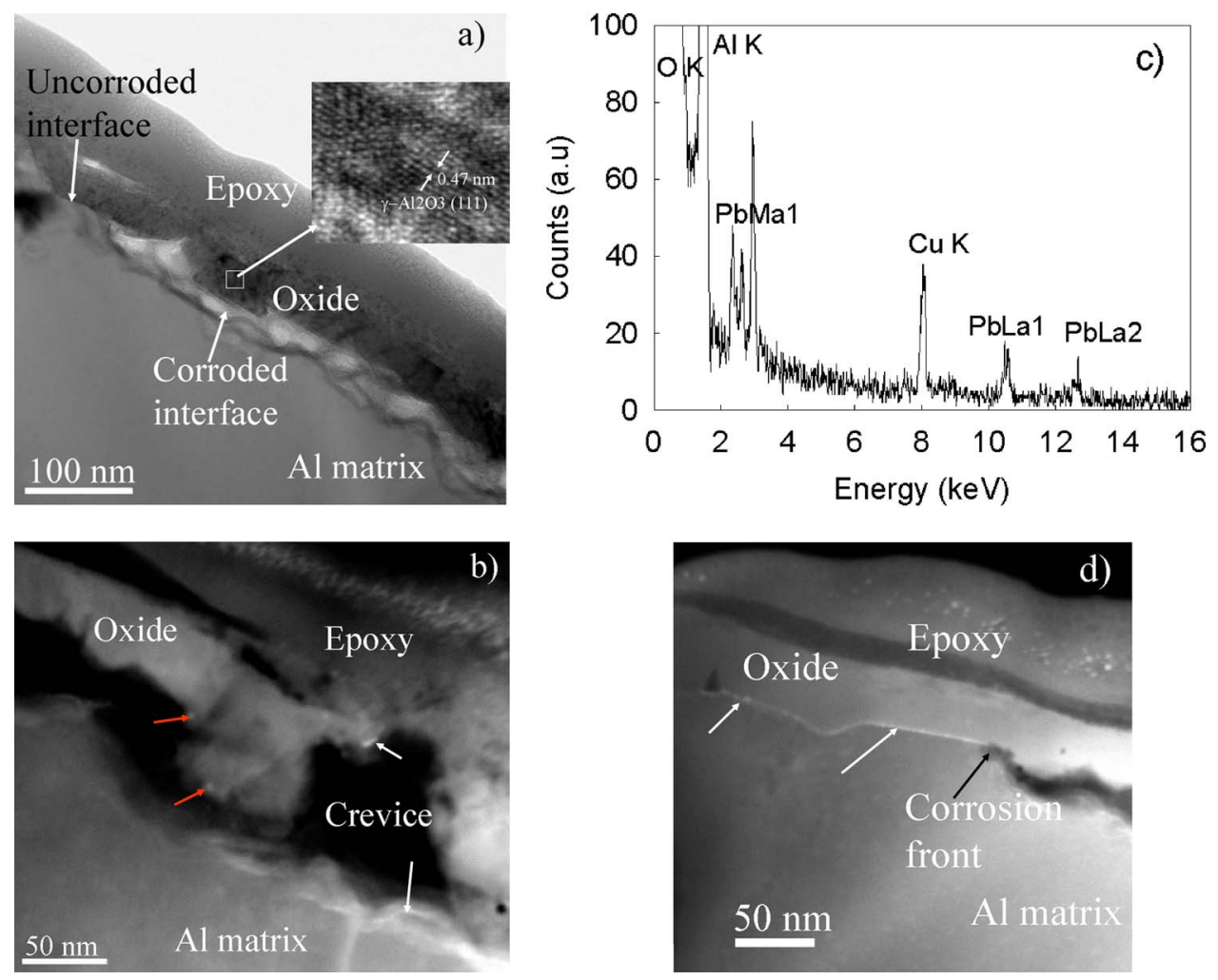

Figure 9. (Color online) STEM images of the cross-sectional sample polarized up to $-0.95 \mathrm{~V}_{\mathrm{SCE}}$. (a) Bright-field image of the corroded area between the metal and undermined oxide. (b) Dark-field STEM image of the corroded area at a higher magnification. The red and white arrows show the $\mathrm{Pb}$ particles and remnants of $\mathrm{Pb}$ film, respectively. (c) EDS analysis of the lower particle (red arrow) on image (b). (d) Dark-field STEM image of the corrosion front, shown by the black arrow and the uncorroded area with intact Pb-rich film ahead of the front, giving a bright contrast. The white arrows show the intact $\mathrm{Pb}$ film. ent area, showing the $\mathrm{Pb}$ particles in the crevice together with corrosion products. The size of particles was in the range 10-20 nm. In this figure, the oxide layer cannot be distinguished visually from the epoxy layer still adhering to the surface, although it is present together with the epoxy according to the EDS analysis of the layer.

\section{Discussion}

The first layer of etching, corresponding to the first oxidation peak, occurred under the thermally formed oxide film upon reaching the first breakdown potential, thereby undermining the film over most of the surface. Etching of the aluminum surface followed the metallic $\mathrm{Pb}$ nanolayer at the metal-oxide interface, discussed in detail in earlier work, ${ }^{7}$ as a result of the anodic activation caused by the film. The $\mathrm{Pb}$ film forming at the thermal oxide-metal interface during heat-treatment reduced the natural bonding of the protective indigenous oxide to the aluminum metal surface. However, electrochemical activation was revealed by acid etching of the surface, the acidity being produced by hydrolysis of aluminum. The first-stage corrosion of aluminum also caused the destruction of the $\mathrm{Pb}$ film. Nanoparticles of $\mathrm{Pb}$ were observed in the crevice formed, as reported earlier. ${ }^{4}$ After the first stage of corrosion, the $\mathrm{Pb}$ film was no longer trapped between the oxide and aluminum, and it rolled up into nanosize particles. ${ }^{4}$ However, remnants of the film were still present in the crevice.

As the $\mathrm{Pb}$ film was destroyed during the first layer of attack over most of the surface, the polarization behavior exhibited a tendency for repassivation. The thickness of the crevice formed between the oxide and the metal as a result of undermining of the oxide estimated from the polarization curves was $\sim 50 \mathrm{~nm}$, which agrees with the TEM observations. This is much thicker than the original $\mathrm{Pb}$ film because the activated surface has to corrode to provide enough dissolved aluminum at the existing $\mathrm{pH}$, such that a stable passive film can again form on the corroding surface as the solubility of the passivating aluminum hydroxide is exceeded at the metal surface in the crevice. This is evidenced in the polarization curve by the onset of passivation, following the first oxidation peak. Because the solution in the crevice is expected to remain acidic, the passivation was not complete and crevice corrosion commenced as the following stage of corrosion when the potential was further increased, as was visible from the in situ video observations and verified by ex situ TEM observations. The presence of activating $\mathrm{Pb}$ nanoparticles and film remnants may be an additional factor causing the second stage. $\mathrm{Pb}$ particles were also reported to cause activation of aluminum. ${ }^{4,6}$ However, the particles are not as effective as the film because the contact area with the surface is smaller.

A second passivation occurred after crevice corrosion attacked the entire surface, giving a rougher surface relative to the first stage of oxidation. The fact that the amount of metal etched during this stage was larger than the first stage was also evident from the amount of charge passed calculated from the area under the second oxidation peak and verified by TEM observation of the corroded thickness. The observations suggest that the second stage of corrosion is controlled by factors prevalent in conventional crevice corrosion of aluminum, as opposed to the highly superficial nature of the first stage, which was controlled by anodic activation of the surface by the thermally segregated $\mathrm{Pb}$ nanofilm. The larger extent of attack resulted in more intense hydrogen evolution compared to the first stage, which detached the loosely bound oxide mechanically with further increase of the potential. Both phenomena contributed to the onset of the second passivation. This was followed at yet higher potentials by pitting corrosion of the bulk material, which became exposed by the previous stages of corrosion. The potential for the onset of bulk pitting corresponded well with the expected value for the critical pitting potential of pure aluminum in $5 \% \mathrm{NaCl}$ solution at $25^{\circ} \mathrm{C}\left(-0.78 \mathrm{~V}_{\mathrm{SCE}}\right){ }^{9}$

The surface grain boundaries were observed to act as a physical barrier for corrosion propagation in this work, rather than being active corrosion sites. The barrier develops as a result of grain growth with height difference of up to $0.5 \mu \mathrm{m}$ between the adjacent grains. The grain boundaries are known to be sites for $\mathrm{Pb}$ segregation. However, the segregation occurs in the form of particles rather than film. ${ }^{11}$ Thus, a physical barrier is formed by the grain boundaries against corrosion propagation analogous to the scribe used to prevent crevice corrosion at the edges of the specimen holder.

These observations thus provide a better understanding of corrosion of aluminum related to $\mathrm{Pb}$ segregation to the surface by 

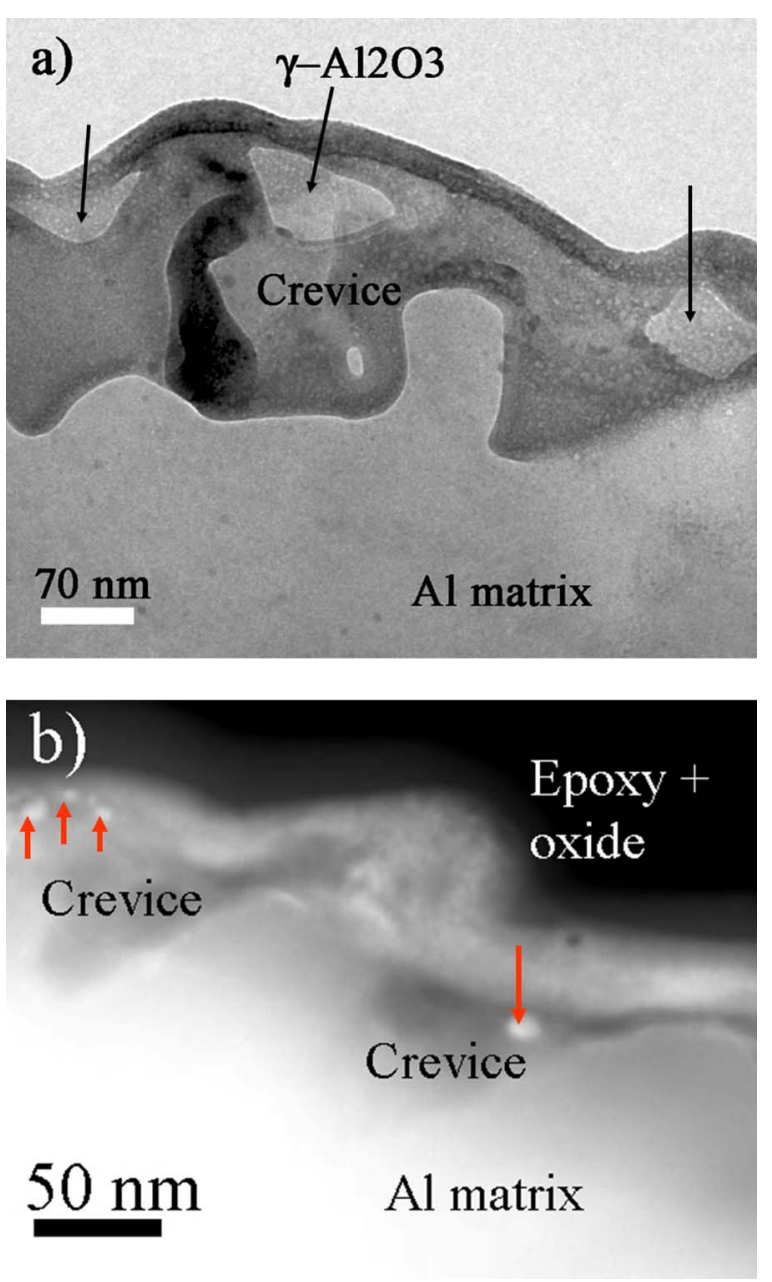

Figure 10. (Color online) (a) STEM micrograph of the cross-sectional sample polarized up to $-0.88 \mathrm{~V}_{\mathrm{SCE}}$, showing the corrosion morphology after the second layer of attack, including remnants of thermally formed $\gamma-\mathrm{Al}_{2} \mathrm{O}_{3}$ oxide indicated by black arrows. (b) Dark-field STEM image showing $\mathrm{Pb}$ particles, indicated by a red arrow, in the crevice formed between the thermally formed oxide and metal.

heat-treatment. ${ }^{1-7}$ Figure 11 schematically summarizes both the earlier and the present results. The observations explain the role of the nearly continuous $\mathrm{Pb}$ nanofilm segregated between the thermally formed oxide and the aluminum metal and the role of $\mathrm{Pb}$ nanoparticles, which were segregated discretely along the oxide-metal interface, ${ }^{7}$ as sketched in Fig. 11a. The continuous film is by far more important than the discrete particles in activating the surface because it wets the metal, whereas the particles provide a comparatively small contact area with the metal substrate. The $\mathrm{Pb}$ particles formed after the first stage of etching, as sketched in Fig. 11b, are therefore not as effective as the film in activating the surface. Many of the particles observed in the corroded area, moreover, were not in contact with the metal surface.

A similar phenomenon of enrichment by such particles was reported earlier regarding the activation of aluminum by $\mathrm{Pb}$ segregated as a result of heat treating similar model alloys in an oxygenfree environment. ${ }^{5}$ There was virtually no oxidation of the surface in this case, and the thermal $\gamma-\mathrm{Al}_{2} \mathrm{O}_{3}$ crystalline film did not form. As a result, the $\mathrm{Pb}$ film could not form either, and $\mathrm{Pb}$ was segregated only in the form of particles, as sketched in Fig. 11c. Such a surface is not activated to the same degree as the surface oxidizing during heat-treatment to form the $\gamma-\mathrm{Al}_{2} \mathrm{O}_{3}$ film.

The foregoing discussion brings forth the question about the role of $\gamma-\mathrm{Al}_{2} \mathrm{O}_{3}$ and grain growth in the formation of the $\mathrm{Pb}$ nanofilm.

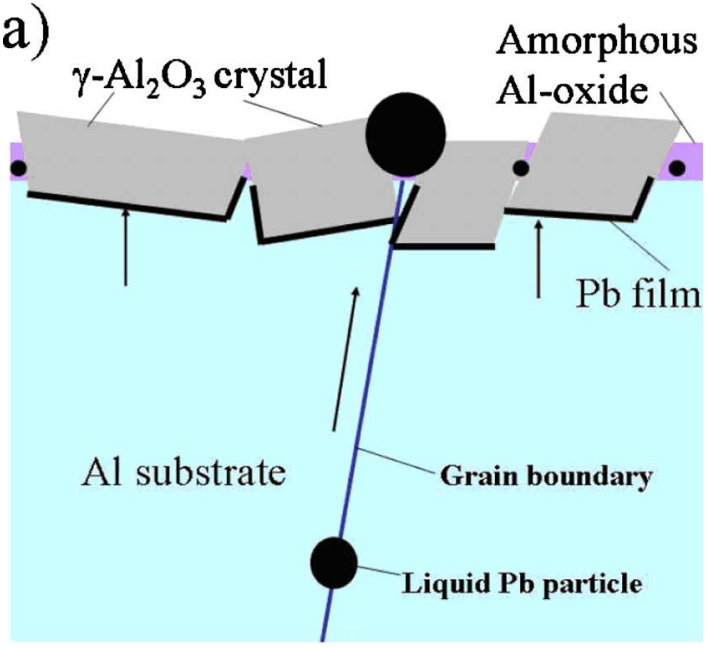

b)

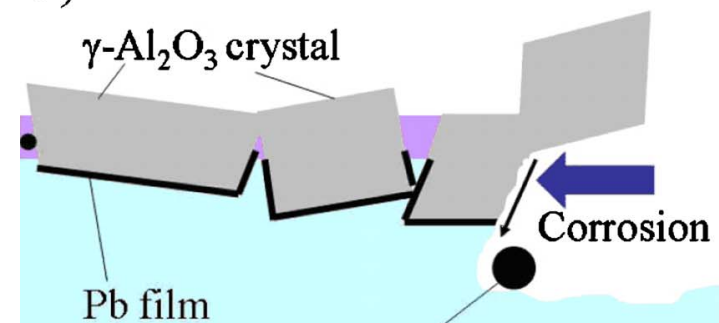

$\mathrm{Pb}$ particle (nonwetting)

Al substrate

c)

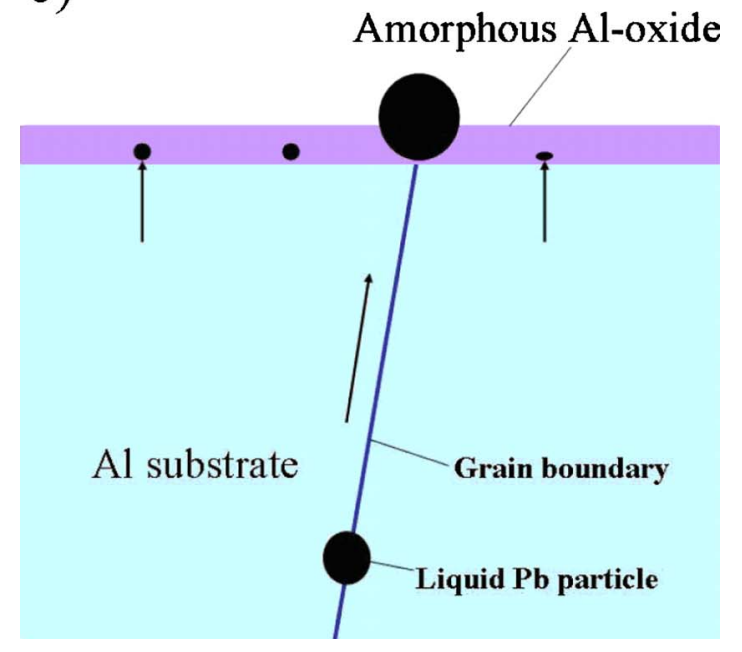

Figure 11. (Color online) Schematic diagram describing (a) the mechanism of $\mathrm{Pb}$ segregation during annealing at $600^{\circ} \mathrm{C}$ in air, (b) first layer of corrosion following the $\mathrm{Pb}$ nanofilm formed during annealing, and (c) segregation of $\mathrm{Pb}$ particles by annealing in the absence of air. (a) In the presence of air, a $\mathrm{Pb}$-rich film segregates as a result of trapping of $\mathrm{Pb}$, diffusing to the surface from the aluminum substrate between the aluminum substrate and $\gamma-\mathrm{Al}_{2} \mathrm{O}_{3}$ crystals growing into the aluminum substrate. (c) In the absence of oxygen, the $\mathrm{Pb}$-rich film cannot form in the absence of growth of $\gamma-\mathrm{Al}_{2} \mathrm{O}_{3}$ crystals on the aluminum surface. 
The film is probably formed by the enrichment of $\mathrm{Pb}$ present in the aluminum surface crystals directly by the selective oxidation of aluminum to form the $\gamma-\mathrm{Al}_{2} \mathrm{O}_{3}$ film during heat-treatment in air at $600^{\circ} \mathrm{C}$. Segregation of metallic $\mathrm{Pb}$ in the liquid state along the grain boundaries of $\mathrm{Al}-\mathrm{Pb}$ as a result of heat-treatment was demonstrated by in situ TEM studies. ${ }^{11}$ Enrichment of $\mathrm{Pb}$ at the metal-oxide interface probably follows a similar procedure. At the same time, the $\gamma-\mathrm{Al}_{2} \mathrm{O}_{3}$ crystals grow into the metal by oxidation at the $\gamma-\mathrm{Al}_{2} \mathrm{O}_{3}$-metal interface. ${ }^{10}$ Selective oxidation of aluminum during this process may also contribute to $\mathrm{Pb}$ enrichment at the metal-oxide interface. The $\mathrm{Pb}$ film is formed by the entrapment of surface enriched atoms between the metal and oxide crystals. The thermal oxide reaches a terminal thickness of $\sim 50 \mathrm{~nm}$ in $\sim 1 \mathrm{~h}^{2,5}$ The thickness of the $\mathrm{Pb}$ film does not increase with increasing time of heat-treatment. However, $\mathrm{Pb}$ continues to migrate to the surface by prolonged heat-treatment, segregating in the form of particles at the pores existing between the $\gamma-\mathrm{Al}_{2} \mathrm{O}_{3}$ crystals. ${ }^{5}$ The thickness of the $\mathrm{Pb}$ film is thus determined by the properties of the interface formed between the $\gamma-\mathrm{Al}_{2} \mathrm{O}_{3}$ crystals and aluminum metal. This is verified also by the fact that the anodic polarization curve of activated $\mathrm{Al}-\mathrm{Pb}$ alloys in chloride solution is not affected by the amount of $\mathrm{Pb}$ present in the alloy. ${ }^{2} \mathrm{~Pb}$ concentrations in the range from 5 to 50 $\mathrm{ppm}$ were shown to give nearly the same polarization behavior. The time of heat-treatment at $600^{\circ} \mathrm{C}$ beyond a certain limit does not affect the polarization curve either, also indicating that the $\mathrm{Pb}$ film reaches a terminal thickness or continuity during the first $1 \mathrm{~h}$ of heat-treatment at $600^{\circ} \mathrm{C}$, and it is not affected by prolonged heattreatment after that limit is reached.

\section{Conclusions}

Two anodic oxidation peaks are normally observed during anodic polarization in chloride solutions of aluminum alloys that contain trace amounts of $\mathrm{Pb}$ and are anodically activated by heat-treatment at $600{ }^{\circ} \mathrm{C}$ as a result of segregation of a $\mathrm{Pb}$ nanofilm along the oxide-metal interface. These peaks correspond to two stages of layer attack. The first layer is related to undermining of the thermally formed oxide film by superficial etching of the metal along the $\mathrm{Pb}$ nanofilm. The second layer is a result of crevice corrosion in the crevice formed between the undermined oxide and metal surface. The effectiveness of $\mathrm{Pb}$ segregating in the form of a nearly continuous nanofilm as opposed to the formation of discrete $\mathrm{Pb}$ nanoparticles, by virtue of a significant difference in the size of $\mathrm{Pb}-\mathrm{Al}$ contact area, is demonstrated.

\section{Acknowledgment}

This work was supported by The Research Council of Norway.

Norwegian University of Science and Technology assisted in meeting the publication costs of this article.

\section{References}

1. Y. W. Keuong, J. H. Nordlien, S. Ono, and K. Nisancioglu, J. Electrochem. Soc. 150, B547 (2003).

2. J. T. B. Gundersen, A. Aytac, J. H. Nordlien, and K. Nisancioglu, Corros. Sci., 46, 265 (2004).

3. J. T. B. Gundersen, A. Aytac, S. Ono, J. H. Nordlien, and K. Nisancioglu, Corros Sci., 46, 697 (2004).

4. Y. Yu, Ø. Sævik, J. H. Nordlien, and K. Nisancioglu, J. Electrochem. Soc., 152, B327 (2005).

5. Ø. Sævik, J. H. Nordlien, Y. Yu, and K. Nisancioglu, J. Electrochem. Soc., 152, B334 (2005)

6. Z. Jia, B. Graver, J. C. Walmsley, J. K. Solberg, and K. Nisancioglu, J. Electrochem. Soc., 155, C1 (2008).

7. J. C. Walmsley, Ø. Sævik, B. Graver, R. Mathiesen, and K. Nisancioglu, J. Electrochem. Soc., 154, C28 (2007).

8. Z. Zhao and G. S. Frankel, Corros. Sci., 49, 3064 (2007).

9. K. Nisancioglu and H. Holtan, Corros. Sci., 18, 835 (1978)

10. K. Shimizu, R. C. Furneaux, G. E. Thompson, G. C. Wood, A. Gotoh, and K. Kobayashi, Oxid. Met, 35, 427 (1991).

11. H. Gabrisch, U. Dahmen, and E. Johnsen, Microsc. Microanal., 4, 286 (1998). 